\title{
Microbial Fouling of a Reverse Osmosis Municipal Water Treatment System
}

\author{
Steven J. Wright, Jeremy D. Semrau*, David R. Keeney
}

\begin{abstract}
Microbial fouling of a municipal water treatment system using reverse osmosis was investigated. From a combination of growth and molecular assays, it was discovered that the prefilter unit concentrated and facilitated microbial growth, and such growth led to microbial fouling of the reverse osmosis unit. Few cells were observed in the prefilter influent, but substantial microbial contamination was observed in the prefilter effluent, and this correlated with increasing headloss across the prefilter. The effluent caused microbial fouling of the leading elements of the reverse osmosis unit, as determined by reduced permeate flow, analysis of the elements, and assays of the membrane foulant. Both the introduction of microorganisms to the reverse osmosis unit from the prefilter unit and headloss across the prefilter could be effectively controlled through cleansing of the prefilter housing unit with sulfuric acid. Such treatments must be performed at appropriate intervals to prevent subsequent microbial growth in the prefilter unit. Water Environ. Res., 80, 703 (2008).
\end{abstract}

KEYWORDS: reverse osmosis, microbial fouling, filtration. doi: $10.2175 / 106143008 \times 276697$

\section{Introduction}

To meet increasing demands for potable water from a variety of sources, reverse osmosis and nanofiltration are being used more extensively throughout the world, including for desalination of seawater and reclamation of wastewater (Bartels et al., 2005). Although many of these systems are quite large, including a plant capable of producing $375000 \mathrm{~m}^{3} / \mathrm{d}$ in Kuwait (Water Technology Net, 2008), reverse osmosis has also been used by municipalities for production of drinking water without the need of more traditional lime softening. One example of this is the decision by a small municipality in the northeast United States, with a population of 5000, to put into operation a reverse osmosis system for the delivery of up to $4000 \mathrm{~m}^{3} / \mathrm{d}$ of finished water. The water plant was part of the need to provide expanded water capacity, but the reverse osmosis treatment was added as a result of the high hardness in the well water used as the water supply (approximately $500 \mathrm{mg} / \mathrm{L}$ [500 ppm]). Problems were experienced with fouling of the reverse osmosis membranes since the beginning of plant operation, resulting in a lack of ability to supply an adequate supply of softened water to the drinking water system. The complete set of reverse osmosis membranes was replaced twice in approximately the first 2 years of operation, as a result of the inability to clean the membranes sufficiently to restore adequate permeate production.

Department of Civil \& Environmental Engineering, University of Michigan, Ann Arbor, Michigan.

* 1351 Beal Avenue, Department of Civil \& Environmental Engineering, University of Michigan Ann Arbor, Michigan 48109-2125; e-mail: jsemrau@umich.edu.
Here, the source for the fouling of the reverse osmosis membranes is identified, and operational modifications to achieve better and more consistent performance are suggested. From a variety of analyses, for this municipal treatment system, microbial fouling was likely responsible for the impaired performance, and inclusion of simple disinfection procedures may limit the future effect of such fouling.

\section{Materials and Methods}

Sample Collection. A schematic of the reverse osmosis treatment facility examined is shown in Figure 1. There are two independent treatment trains of this type. As noted in Figure 1, initial water samples were aseptically collected in early August 2006, from various locations within the water treatment system, noted by S-1 to S-5, from the unit that was in operation. These included samples from the well source (S-1) and the pipeline that connects the reservoir receiving the outflow from the greensand filters and the reverse osmosis units (S-2). This pipeline contains a set of 5- $\mu \mathrm{m}$ prefilters located just upstream of the reverse osmosis unit; the above-mentioned samples were collected upstream from these prefilters. Additional samples were collected between the prefilters and the reverse osmosis system (S-3), the permeate flow of the reverse osmosis unit (S-4), and the effluent concentrate from the reject water from the treatment process $(\mathrm{S}-5)$. All samples were stored on ice before spreading in nutrient agar for cell enumeration.

Additional water samples were collected from August to October 2007, immediately upstream and downstream of the prefilters (S-2 and S-3 in Figure 1), as described above. Furthermore, immediately before and after disinfection with sulfuric acid $\left(\mathrm{H}_{2} \mathrm{SO}_{4}\right)$ (see below), samples of biofilms forming on the interior of the prefilter housing units were aseptically collected using sterile cotton swabs. The swabs were then placed in $3 \mathrm{~mL}$ of Luria-Bertani medium and incubated at $30^{\circ} \mathrm{C}$ overnight. Microbial growth was monitored by measuring the optical density at $600 \mathrm{~nm}\left(\mathrm{OD}_{600}\right)$ using a 20 GENESYS Spectrophotometer (Spectronic Unicam, Rochester, New York).

Headloss Measurements. Water pressure in the influent and effluent lines of the prefilter was recorded on a daily basis, to determine headloss across the prefilter.

Enumeration and Characterization of Microbial Contamination. Bacteria were enumerated by spreading $100 \mu \mathrm{L}$ of inoculum from the various points noted in Figure 1 on sterile Petri dishes filled with sterile nutrient agar (Oxoid Ltd., Hampshire, United Kingdom). Plates were then incubated for 3 days at $30^{\circ} \mathrm{C}$, and colony-forming units (CFUs) were counted. Sample colonies were subsequently tooth-picked from the dishes and grown overnight in $2 \mathrm{~mL}$ of sterile Luria-Bertani medium (Sambrook et al., 1989). These cultures were then centrifuged at approximately 


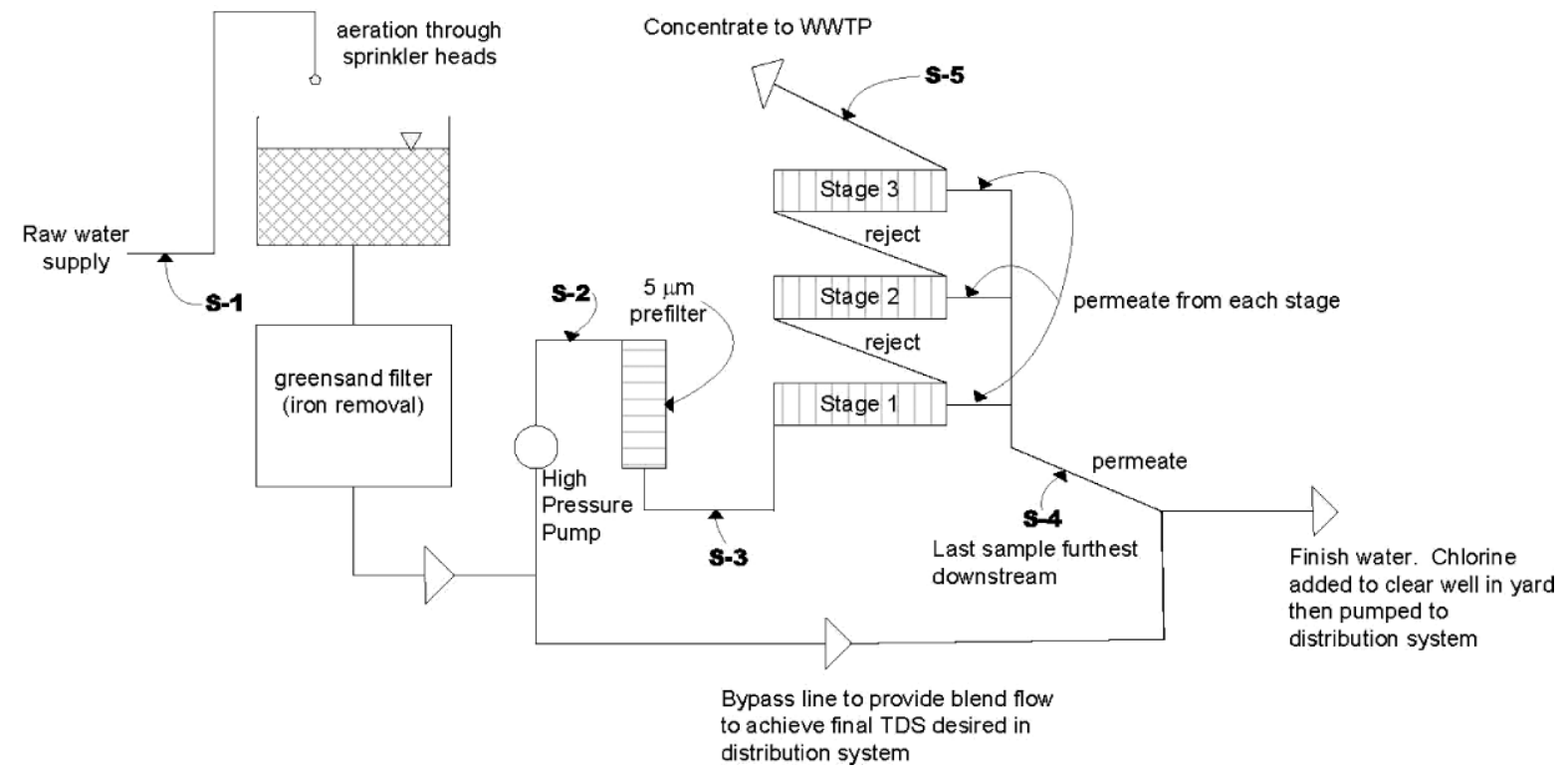

Figure 1-Schematic of the reverse osmosis treatment facility examined in this study. Locations of aseptically collected water samples are noted as S-1 through S-5 (TDS = total dissolved solids).

$18000 \times \mathrm{g}$ for 2 minutes. The pellet was resuspended in $400 \mu \mathrm{L}$ buffer (50 mM Tris-HCl pH 8.0, 10 mM EDTA, 100 mg/L RNAse A). Approximately $400 \mathrm{mg}$ of silica beads (0.1-mm diameter) were added, and the slurry was vortexed for 5 minutes. The slurry was then centrifuged at approximately $18000 \times \mathrm{g}$ for 1 minute. The supernatant was then stored as crude DNA extract.

Polymerase chain reaction (PCR) was performed with Invitrogen Taq Polymerase, according to the manufacturer's instructions (Invitrogen Corporation, Carlsbad, California). The temperature profile was as follows: initial denaturation $=94^{\circ} \mathrm{C}$ for 3.5 minutes, 30 cycles of $94^{\circ} \mathrm{C}$ for 30 seconds, $55^{\circ} \mathrm{C}$ for 30 seconds, and $72^{\circ} \mathrm{C}$ for 1 minute, followed by polishing at $72^{\circ} \mathrm{C}$ for 7 minutes. Approximately $1 \mu \mathrm{L}$ of crude extract was used for the template, and the primers were 16S_27f (AGAGTTTGATCMTGGCTCAG) and 16S_1492r (TACGGYTACCTTGTTACGACTT), where $\mathrm{M}=\mathrm{C}$ or $\mathrm{A}$ and $\mathrm{Y}=\mathrm{T}$ or $\mathrm{C}$. After PCR, the reaction was cleaned with the Qiagen PCR purification kit (Qiagen, Valencia, California) and the eluant was sent directly for sequencing at The University of Michigan DNA Sequencing Core (Ann Arbor, Michigan) with $16 \mathrm{~S} \_27 \mathrm{f}$ and $16 \mathrm{~S} \_1492 \mathrm{r}$ as sequencing primers. The DNA sequences were analyzed by a nucleotide-nucleotide BLAST search against the nr database (http://www.ncbi.nlm.nih.gov/blast). When more than $75 \%$ of the top 20 hits for a sequence matched a particular genus, that genus was assigned to the sample.

Disinfection of Prefilter Housing. Following up on the initial sampling activity in 2006, additional sampling was performed starting in early August 2007. This effort was intended to isolate the source of the microbial fouling, with early phases of this investigation indicating the stainless-steel prefilter housings as a likely source. To remove any microbial contamination (i.e., biofilms) that may have developed over time in the prefilter housing leading to microbial fouling of both the reverse osmosis elements and prefilters, the entire water treatment system was taken offline on September 13, 2007. The prefilter unit was then filled with $60 \%$ (v/v) $\mathrm{H}_{2} \mathrm{SO}_{4}$, driving the $\mathrm{pH}$ to 0.5 , and incubated for 1 hour. Samples of the inflow and outflow to the prefilters and swabs of the interior of the prefilter housing were taken, both before and after this disinfection step.

Reverse Osmosis Membrane Analyses. Two reverse osmosis elements were sent to Avista Technologies (San Marcos, California) for fouling analyses in October 2006. One element was taken from stage 1 of the reverse osmosis system, while the other was taken from stage 3 (Figure 1). Both elements were visually inspected, permeate flow was measured, and Fourier transform infrared (FTIR) analysis of the elements and loss-on-ignition assays of the foulant were performed.

\section{Results}

As shown in Table 1, which presents the results of samples collected in August 2006, a clear and specific distribution of microorganisms was found. The raw well water was found to have no measurable microbial contamination (or, at the very least, no general heterotrophs, because no growth on nutrient agar was observed). Furthermore, no measurable microbial contamination was observed in the effluent of the greensand filter used for iron removal. However, a substantial number of microorganisms was observed downstream of the 5- $\mu \mathrm{m}$ prefilter at a level of $117 \mathrm{CFU} /$ $100 \mu \mathrm{L}$. The dramatic increase indicated that the raw water had a very low, but significant, amount of microorganisms and that the prefilter facilitated the concentration and possibly the growth of these cells. Subsequently, breakthrough of these cells was evident from the large numbers of cells in the prefilter effluent. Finally, the reverse osmosis units facilitated the removal of these cells, with the reverse osmosis concentrate having a substantially higher cell density than the reverse osmosis permeate. It is interesting to note, however, that the reverse osmosis permeate also had a measurable microbial content $(11 \mathrm{CFU} / 100 \mu \mathrm{L})$, possibly indicating that the reverse osmosis membrane integrity was compromised; another possibility is that the two reverse osmosis units were used on an alternating basis, potentially allowing for microbial growth in the stagnant unit not in use. 
Table 1-Distribution of microbial contamination in the municipal water treatment plant in August 2006.

\begin{tabular}{|c|c|c|}
\hline Sample location & Location description & $\mathrm{CFU} / 100 \mu \mathrm{L}$ \\
\hline S-1 & Raw well water & 0 \\
\hline S-2 & $\begin{array}{l}\text { After green sand filter, before } \\
5-\mu \mathrm{m} \text { prefilter }\end{array}$ & 0 \\
\hline S-3 & $\begin{array}{l}\text { After } 5 \text { - } \mu \text { prefilter, before } \\
\text { reverse osmosis system }\end{array}$ & 117 \\
\hline S-4 & $\begin{array}{l}\text { Permeate from reverse } \\
\text { osmosis system }\end{array}$ & 11 \\
\hline S-5 & $\begin{array}{l}\text { Reverse osmosis concentrate } \\
\text { (sent to wastewater system) }\end{array}$ & 465 \\
\hline
\end{tabular}

To characterize the phylogeny of these cells, 16s rDNA sequence analyses were performed on different colony morphologies observed on the nutrient agar plates, from samples taken directly from a used 5- $\mu \mathrm{m}$ prefilter cartridge. From these studies, four different genera of bacteria could be detected-Chryseobacterium, Ralstonia, Microbacterium; and Pseudomonas. Sequence analyses were also performed on samples from the prefilter effluent and reverse osmosis permeate, with Microbacterium and Pseudomonas also found in these samples.

The Chryseobacterium colonies were medium, yellow, round, smooth, flat, and wet. This genus is a member of the Flavobacteriaceae family. There are currently 13 species of Chryseobacterium, and the type species is Chryseobacterium gleum (Tai et al., 2006). Other species in this genus are Gram-negative nonmotile, nonspore-forming rods. (Kampfer et al., 2003; Tai et al., 2006). Ralstonia colonies that were medium, white, round, smooth, convex, and wet were also isolated. The most well-studied species of the Ralstonia genus is Ralstonia solanacearum, a plant pathogen that causes wilting disease in over 200 plant varieties. The pathogen is especially well-studied, because it affects some important food crops, such as potatoes and tomatoes (Genin and Boucher, 2004). Ralstonia are Gram-negative rods. Additionally, they are nonfermentative and can be motile (Ryan et al., 2006). The Microbacterium colonies that were isolated are orange, round, flat, and wet, with small lobes. Microbacterium are coryneform bacteria, Gram-positive, non-spore-forming aerobic rods, commonly found in both environmental and clinical samples (Funke et al., 1997).

Following confirmation of significant microbial populations within the treatment train, it was decided to perform additional autopsies on the reverse osmosis membrane elements, to confirm the presence of microbial mass in the foulant on the membrane surfaces. With the knowledge that biofouling was a distinct probability, two membrane elements were removed. One of these elements was the leading element in the first stage of the reverse osmosis system, while the second element was one of the last elements in the third stage (Figure 1). The rationale behind this approach was the expectation to find microbiological growth concentrated near the upstream end of the membrane train; thus, there should be a significant difference between the two elements.

From the reverse osmosis element autopsy performed by Avista Technologies, it was observed that the leading element taken from stage 1 showed significant visible orange-colored foulant, while the tailing element from stage 3 showed no visible fouling. Furthermore, the leading element had a permeate flow of approximately $38 \mathrm{~m}^{3} / \mathrm{d}(7 \mathrm{gpm})$ and $93 \%$ salt rejection, with approximately $76-\mathrm{kPa}$ (11-psi) pressure differential. The tailing element had a flowrate of

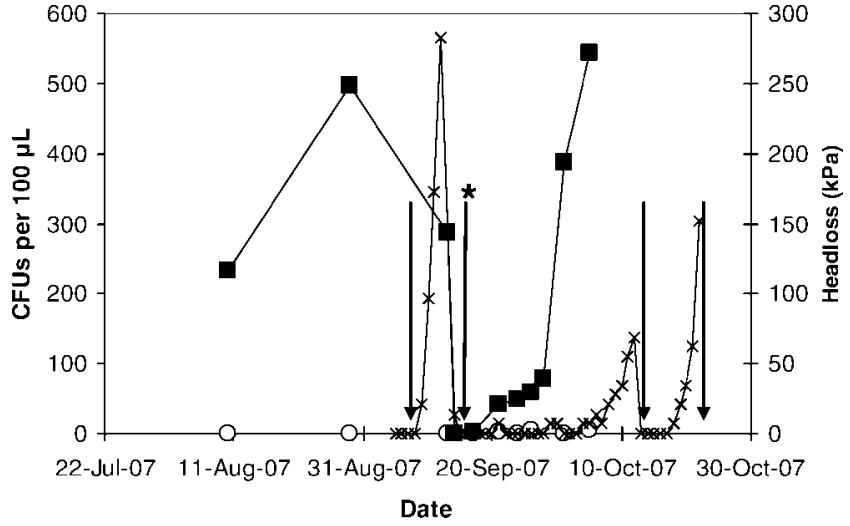

Figure 2-Analyses of the presence of microorganisms in the influent $(O)$ and effluent $(\square)$ of the prefilter unit and headloss $(x)$ across the unit during late summer 2007. Arrows indicate dates of prefilter cartridge replacement (September 4 and 13 and October 13 and 22, 2007). Asterisk indicates disinfection of prefilter housing with sulfuric acid (September 13, 2007).

approximately $39 \mathrm{~m}^{3} / \mathrm{d}(7.2 \mathrm{gpm})$ and $97 \%$ salt rejection, with approximately $28-\mathrm{kPa}(4.0-\mathrm{psi})$ pressure differential. For comparison, normal parameters for these elements are approximately $40 \mathrm{~m}^{3} / \mathrm{d}(7.3 \mathrm{gpm})$ flowrate and $99 \%$ salt rejection, with differential pressures ranging from approximately 21 to $34 \mathrm{kPa}$ (3 to $5 \mathrm{psi}$ ). From these data, it appears that fouling is localized to the leading elements. When loss-on-ignition tests were performed, approximately $82 \%$ of the foulant was lost in the leading element upon ignition, indicating that the foulant was primarily organic in nature. Insufficient foulant was present on the tailing element to perform a loss-on-ignition test. Finally, FTIR analyses showed significant amounts of proteins and carbohydrates in the leading element, while only small amounts were observed in the tailing element (data not shown). Collectively, these data, coupled with the findings of microbial contamination prevalent just upstream of the reverse osmosis elements, suggest that microbial fouling was the primary cause for impaired performance of these elements, particularly the leading elements.

To confirm the finding that microbial contamination increased across the prefilter subunit and support the hypothesis that microbial growth in the prefilter was the source of microbial fouling of the reverse osmosis elements, additional samples were collected from August to October 2007, immediately upstream and downstream of the prefilter. During this time period, significant headloss across the prefilter (i.e., 103 to $276 \mathrm{kPa}$ [15 to $40 \mathrm{psi}$ ), was observed within 10 days following prefilter cartridge installation, necessitating frequent replacement of the prefilters (i.e., on September 4 and 13, 2007, as indicated in Figure 2). Such headloss may be attributed, at least in part, to microbial growth within the prefilter unit housing. To test the hypothesis of microbial contamination within the prefilter unit (i.e., biofilm formation on the prefilter housing), swabs of the interior walls of the prefilter housing unit were collected before and after the unit was disinfected with $\mathrm{H}_{2} \mathrm{SO}_{4}$ on September 13, 2007.

Significant microbial growth was observed from swabs of the prefilter housing. Specifically, before the unit was disinfected with $\mathrm{H}_{2} \mathrm{SO}_{4}$, visible microbial growth (i.e., $\mathrm{OD}_{600}$ of 0.80 ) was observed after 1 day of growth in Luria-Bertani broth. Immediately after acid treatment, no microbial growth was observed from swabs of the 
prefilter housing unit. Also, as can be seen in Figure 2, significant numbers of microorganisms in the prefilter effluent were observed before disinfection, despite very little contamination observed in the prefilter influent line. Immediately after disinfection, microbial contamination was reduced to near-zero levels. However, the concentration of microorganisms was observed to slowly increase over time in the effluent, with a concurrent increase in headloss. Unacceptable headloss (i.e., $>103 \mathrm{kPa}$ [>15 psi]) was not observed for 1 month, whereas headloss as great as approximately $283 \mathrm{kPa}$ (41 psi) was seen within 10 days immediately before disinfection. It is also interesting to note that, despite large numbers of cells in the prefilter effluent, the unit itself was not disinfected when the prefilter cartridges were replaced on October 13, 2007. Subsequent measurements indicated a rapid rate of headloss increase across the prefilter, with the cartridges needing replacement after 9 days, when the headloss was found to be approximately $152 \mathrm{kPa}$ (22 psi).

\section{Discussion}

During the initial phase of plant startup, the performance of the system was inadequate, with the reverse osmosis elements being completely replaced twice within the first 2 years of operation. Upon failure of the second set of membranes, two of the membrane elements were autopsied, in an attempt to identify the source of the fouling. Both elements indicated a reduction in flow through the membrane elements, to approximately 59 to $67 \%$ of specifications. One membrane element was investigated by phase contrast microscopy, and it was estimated that $60 \%$ of the foulant on the membrane surface was composed of microbiological growth. A loss-on-ignition test was performed on the second membrane element, with a resulting $64 \%$ mass loss of the foulant. Despite these findings, it was suggested that the primary cause of membrane fouling was iron precipitation. Part of the rationale for this conclusion was the fact that several months had elapsed between the removal of the membrane elements from the system and the performance of the membrane autopsies, and it was interpreted that apparent biofouling was likely the result of microbiological growth in that intervening time interval. The lack of a firm basis for this conclusion led to the decision to perform the additional testing described above to either confirm this interpretation or find out whether microbial fouling was the major contributing factor to the continuing problems with the reverse osmosis system performance.

To investigate this issue further, water samples were taken at various points of the water treatment plant (Figure 1) for quantification of microbial contamination and characterization of any observed cells. As described in the Results section, a substantial increase in microbial contamination was found in the effluent of the 5 - $\mu \mathrm{m}$ prefilter compared with the influent, and at least four different genera of bacteria compose this contamination. As such, it appears that the prefilter acted to concentrate these cells and also possibly facilitate their growth, such that breakthrough was evident. These genera of bacteria, both Gram-negative and Gram-positive, could then be passed to the reverse osmosis membranes, leading to biofouling and reduced efficiency of reverse osmosis treatment. In particular, it is interesting to note that the visual examination of reverse osmosis elements found the presence of orange-colored fouling that was determined to be organic in nature using FTIR analysis. Given that Microbacterium, as isolated on nutrient plates, were orange in color, and this genera has been discovered in a wide range of environments, including wetlands, soils, and activated sludge, can grow on a variety of carbon sources, and produce organic acids (Collins and Bradbury, 1992; Park et al., 2006), it is likely that these cells are at least partly responsible for the microbial fouling found on the reverse osmosis elements.

It is particularly interesting that, in an investigation of a full-scale reverse osmosis membrane unit, Chen et al. (2004) characterized a diverse microbial community on the surface of the reverse osmosis membranes, of which, a significant fraction (16\% of all isolates) was found to be a Microbacterium sp. This microorganism was further found to readily form biofilms (Pang et al., 2005), suggesting that it may play a significant role in reverse osmosis membrane biofouling. It is interesting to note that a similar strain was isolated here, raising the questions of how significant a role these particular cells may have in fouling reverse osmosis systems and if maintenance strategies should target how best to prevent the infiltration of such cells into reverse osmosis systems, prevent growth within reverse osmosis systems, and/or effectively remove from reverse osmosis membranes.

As part of the additional analyses to determine what was causing system deterioration, two elements were sent to Avista Technologies for further analyses in 2006. Although the casings, seals, glue lines, spacers, and antitelescoping devices were all in good condition, with no evidence of leakage, the exposed membrane and vexar surfaces for the leading element sent for analysis were visibly coated with a light orange foulant. Further analyses using loss-on-ignition to determine the organic content of the foulant indicated that $>80 \%$ was lost, indicating a very high organic content. Finally, FTIR analyses on this sample found a significant amount of protein and carbohydrates, indicated microbial fouling. Such fouling has been known to be possible for some time, particularly for systems used in wastewater treatment (Ridgeway et al., 1983), and a great deal of attention has been focused on laboratory analyses of biofilm development on reverse osmosis membranes (Hersberg and Elimelech, 2007; Jarusutthirak and Amy, 2006; Pang et al., 2005). Less information is readily available on microbial fouling of full-scale reverse osmosis systems used for potable water production, but, from the current analyses, it appears that it can be problematic for such uses, as oligotrophic microbial growth may occur in the system.

Given the demonstration of microbial fouling of the reverse osmosis system, a decision on control of this fouling must be made to optimize the use of these systems for delivery of potable water. One possibility would be to replace the prefilters on a more regular basis, thereby limiting pass-through of microorganisms to the reverse osmosis system. Although such a solution is theoretically possible (there is a practical limitation because of the expense of frequent replacement of the prefilter cartridges), we observed significant microbial contamination in the prefilter effluent very soon after changing prefilter cartridges on September 4, 2007. As such, it appears that biofilm formation on the prefilter housing and/ or piping was occurring, and such growth was at least partially responsible for microbial contamination. To investigate this further, it was decided to both change cartridges and disinfect the prefilter unit with $\mathrm{H}_{2} \mathrm{SO}_{4}$ on September 13, 2007. Strong oxidants, such as chlorine, were not used, as they can damage the polyamide membrane elements (Da Silva et al., 2006; Kwon and Leckie, 2006a, 2006b). As shown in Figure 2, microbial contamination dropped significantly in the prefilter effluent immediately after disinfection. It is interesting to note, however, that microorganisms recolonized the prefilter system, as evidenced by the increase of microorganisms in the prefilter effluent, although it required 3 weeks to achieve numbers of similar magnitude to those observed before disinfection. Subsequent introduction of cells, either from the 
water from the greensand filter and/or sloughing of biofilms in upstream piping areas not disinfected with $\mathrm{H}_{2} \mathrm{SO}_{4}$, likely occurred, with resulting growth in the prefilter system.

\section{Conclusion}

Given these findings and considering that autopsies performed on membrane elements indicated that only the leading element in the first stage exhibited significant biofouling, such microbial fouling may be easily managed through regular disinfection of the complete prefilter and reverse osmosis units. As a diagnostic tool for determining when such tasks should be performed, it is recommended that simple microbial growth assays be performed on the prefilter effluent to the reverse osmosis system, in conjunction with standard measurements of headloss. Such data can help determine not only when prefilters should be replaced, but also the frequency of disinfection of the prefilter unit, and thus reduce the number of times more extensive maintenance procedures must be performed on the reverse osmosis system.

Submitted for publication November 20, 2007; accepted for publication February 26, 2008.

The deadline to submit Discussions of this paper is November 15 , 2008

\section{References}

Bartels, C. R.; Wilf, M.; Andes, K.; Iong, J. (2005) Design Considerations for Wastewater Treatment by Reverse Osmosis. Water Sci. Technol., 51, 473-482.

Chen, C-L.; Liu, W-T.; Chong, M-L.; Wong, M. T.; Ong, S. L.; Seah, H.; Ng, W. J. (2004) Community Structure of Microbial Biofilms Associated with Membrane-Based Water Purification Processes as Revealed Using a Polyphasic Approach. Appl. Microbiol. Biotechnol., 63, 466-473.

Collins, M. D.; Bradbury, J. F. (1992) Chapter 62: The Genera Agromyces, Aureobacterium, Clavibacter, Curtobacterium, and Microbacterium. In The Prokaryotes, 2nd ed., Balows, A., Trüper, H. G., Dworkin, M., Harder, W., Schleifer, K-H. (Eds.); Springer-Verlag: New York, 13551368.

Da Silva, M. K.; Tessaro, I. C.; Wada, K. (2006) Investigation of Oxidative Degradation of Polyamide Reverse Osmosis Membranes by Monochloroamine Solutions. J. Membr. Sci., 228, 375-382.
Funke, G.; von Graevenitz, A.; Clarridge, J. E.; Bernard, K. A. (1997) Clinical Microbiology of Coryneform Bacteria. Clin. Microbiol. Rev., 10, 125-159.

Genin, S.; Boucher, C. (2004) Lessons Learned from the Genome Analysis of Ralstonia solanacearum. Ann. Rev. Phytopathol., 42, 107-134.

Hersberg, M.; Elimelech, M. (2007) Biofouling of Reverse Osmosis Membranes: Role of Biofilm-Enhanced Osmotic Pressure. J. Membr. Sci., 295, 11-20.

Jarusutthirak, C.; Amy, G. (2006) Role of Soluble Microbial Products (SMP) in Membrane Fouling and Flux Decline. Environ. Sci. Technol., 40, 969-974.

Kampfer, P.; Dreyer, U.; Neef, A.; Dott, W.; Busse, H. J. (2003) Clinical Microbiology of Coryneform Bacteria. Int. J. Syst. Evol. Microbiol., 53, 93-97.

Kwon, Y-N.; Leckie, J. O. (2006a) Hypochlorite Degradation of CrossLinked Polyamide Membranes I. Changes in Chemical/Morphological Properties. J. Membr. Sci., 283, 21-26.

Kwon, Y-N.; Leckie, J. O. (2006b) Hypochlorite Degradation of CrossLinked Polyamide Membranes I. Changes in Hydrogen Bonding Behavior and Performance. J. Membr. Sci., 282, 456-464.

Pang, C. M.; Hong, P.; Guo, H.; Liu, W-T. (2005) Biofilm Formation Characteristics of Bacterial Isolates Retrieved from a Reverse Osmosis Membrane. Environ. Sci. Technol., 39, 7541-7550.

Park, H. Y; Kim, K. K.; Jin, L.; Lee, S-T. (2006) Microbacterium paludicola sp. nov., a Novel Xlanolytic Bacterium Isolated from Swamp Forest. Int. J. Syst. Evol. Microbiol., 56, 535-539.

Ridgeway, H. F.; Kelly, A.; Justice, C.; Olson, B. H. (1983) Microbial Fouling of Reverse-Osmosis Membranes Used in Advanced Wastewater Treatment Technology: Chemical, Bacteriological, and Ultrastructural Analyses. Appl. Environ. Microbiol., 45, 1066-1084.

Ryan, M. P.; Pembroke, J. T.; Adley, C. C. (2006) Ralstonia pickettii: A Persistent Gram-Negative Nosocomial Infectious Organism. J. Hosp. Infect., 62, 278-284.

Sambrook, J.; Fritsch, E. F.; Sambrook, J. (1989) Molecular Cloning: A Laboratory Manual; Cold Spring Harbor Laboratory: Cold Spring Harbor, New York.

Tai, C.; Chen, H.; Yokota, A.; Kuo, H.; Lee, F.; Lo, C. (2006) Chryseobacterium taiwanense sp. nov., Isolated from Soil in Taiwan. Int. J. Syst. Evol. Microbiol., 56, 1771-1776.

Water Technology Net (2008) Sulaibiya Wastewater Treatment and Reclamation Plant, Kuwait. http://www.water-technology.net/projects/ sulaibiya (accessed March 2008). 